\title{
AS EXPRESSÕES DO PÁTHOS NO FRAGMENTO 31 (PAGE), DE SAFO
}

Ricardo de Souza Nogueira (UFRJ - Faculdade de Letras; PPGLC/UFRJ)

\section{RESUMO}

A proposta deste trabalho é discorrer sobre algumas possibilidades de análise do poema de Safo conhecido com Fragmento 31 (Page), mais precisamente, sobre as construções de expressões amorosas presentes na obra. Considera-se possível, em meio aos problemas constantes no texto, extrair do poema seus significados essenciais, que são inerentes ao tema do páthos amoroso tão recorrente na obra da poetiza. O estudo apresenta ainda uma proposta de tradução do poema em pauta e uma análise de sua estrutura. Para tanto, utilizou-se o texto grego editado por Page, assim como os comentários e a interpretação que esse helenista faz a respeito da obra.

Palavras-chave: páthos, Fragmento 31 (Page), Safo, tradução.

\begin{abstract}
The proposal of this paper is to talk about some possibilities of analysis of Sappho's poem known as Fragment 31 (Page), more exactly, about the constructions of amorous expressions in the work. It is considered possible, in spite of existing problems in the text, to extract from the poem its essential meanings that are inherent to the theme of amorous páthos so frequent in the poetess' work. The study also brings a proposal of translation of the poem in question and an analysis of its structure. For this, it was used the Greek text edited by Page, and also the commentaries and the interpretation which this Hellenist makes about the work.
\end{abstract}

Keywords: páthos, Fragment 31 (Page), Sappho, translation.

Safo nasceu em Éresos, uma das cinco cidades da Ilha de Lesbos, entre 630 e 609 a.C.. A poetiza era, portanto, uma lesbiás, -ádos पou lesbís, -ídos, lesbiense, lésbia, adjetivos de tema em dental que serviam para fazer referência às mulheres nascidas na ilha. Apesar de ser uma derivação perfeitamente lógica, não é atestado nas obras remanescentes da Grécia antiga algo semelhante ao adjetivo lésbico(a), formado pelo sufixo -ico, proveniente do grego ikos, que, por indicar relação, serve para fazer 
menção a agentes de determinada região, ao ser substantivado. ${ }^{10}$ Os termos lesbiás】e lesbís não trazem de modo algum a conotação de homossexualidade feminina dos tempos atuais, presente mais precisamente no adjetivo lésbica em português. ${ }^{11}$ Mesmo que forçosamente possa se falar, nesse contexto, de um cidadão lésbico ou de uma poesia lésbica, isso seria simplesmente falar, respectivamente, de um nativo da Ilha de Lesbos e de uma arte poética que se desenvolveu nesta região, que foi o centro da cultura $E^{1}$ ólica. Nesta ilha, a liberdade dada às mulheres era maior do que no restante da Grécia, e isso explica o surgimento de um fenômeno literário como Safo. $\mathrm{Na}$ Antiguidade, por conta dessa liberdade, as mulheres de Lesbos começaram a adquirir um significado pejorativo, havendo, inclusive, entre os gregos, o verbo lesbiázein, que, com a presença do sufixo imitativo -azein, significa etimologicamente imitar as lésbias, agir como uma lesbiense. Com o direcionamento semântico para o âmbito feminino, no século V a.C. o verbo apresenta os significados de fazer libertinagem como as lésbias, agir como prostituta, ideia que se apresenta, sobretudo, na comédia clássica. ${ }^{12}$

O meio em que Safo se desenvolveu lhe possibilitou uma vida livre, feliz e próspera, que pode ser percebida em seus poemas amorosos, portadores de uma requintada arte que evidencia não só o talento de uma grande poetiza, mas também o conhecimento que possuía em seu ofício de mestra da mousiké, arte das musas. Ela era uma espécie de professora, cuja competência incluía ensinar a suas jovens alunas música, canto, dança e maneiras de viver em felicidade com o marido. Em suma, Safo ensinava, em sua escola de mulheres, a arte do bem viver. A poetiza se casou e possuía uma filha, chamada Cleis.

\footnotetext{
${ }^{10} \mathrm{Cf}$. o adjetivo helenikós, é, ón helênico(a), que substantivado forma o agente ho helenikós, o helênico, ou seja, o homem grego. Portanto, o adjetivo lesbikós, é, ón seria uma construção perfeitamente lógica e possível, assim como o agente ho lesbikós.

${ }^{11} \mathrm{O}$ uso do termo lésbica, ou melhor, lesbian, já que se trata de uma obra em inglês, para designar o homossexualismo feminino tem uma de suas primeiras ocorrências em 1890, em uma obra médica denominada Billing's Medical Dictionary. Para uma discussão mais aprofundada sobre o termo, ver Hallet (p. 129 e segs.).

${ }^{12}$ Um exemplo bem pitoresco se encontra na comédia Rãs (v. 1308), de Aristófanes, em uma fala em que Dioniso, respondendo a Ésquilo, que havia chamado a musa de Eurípides para entoar uma música, diz:

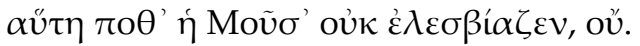

Nenhuma vez essa Musa fez sexo como as lesbienses, não.

Soares (p. 187), citando Sommerstein (Aristophanes Frogs. Oxford: Aris and Phillips, 1996, p. 274), diz em nota de sua tradução de Rãs que a fala de Dioniso, tendo duplo sentido, serve tanto para ridicularizar a Musa da música de Eurípides quanto para dizer que tal Musa não poderia ter relações sexuais como as lesbienses, devido talvez à sua feiúra. Pela presença do pronome demonstrativo haúte, pode-se perceber que a representação cênica aponta para a presença de alguma pessoa feia em cena.
} 
O conceito de poíesis, poesia, entendida etimologicamente como a própria ação de criar $^{13}$, é a força criadora que Safo possuía em constante movimento e mutação dentro de si e que lhe permitia criar versos imortais, com um caráter íntimo e extremamente subjetivo. Sendo um poder criador, a poesia pode aparecer como um dos meios mais satisfatórios para expressar um sentimento humano. Um livro técnico poderia tentar definir o medo, mencionando a sua causa, baseada na presença de um objeto de terror, e o excesso de adrenalina, elemento físiológico que se faz presente no ápice desse sentimento, mas a poesia, sendo manejada por bons autores, com um simples verso, pode dizer algo estético mais profundo do que qualquer estudo técnico, pois, enquanto esse trabalha apenas com aquilo que é comprovado cientificamente na experiência, a poesia faz uso dos elementos mais recônditos da alma humana, chegando a expressões que não podem ser explicadas em bases científicas. Safo era uma mestra imbatível neste tipo de expressão, e, para exemplificar isso, basta dizer que, paradoxalmente, ela versou sobre o amor melhor do que qualquer outro poeta, antes ou depois dela, exatamente porque nunca definiu tal sentimento em uma frase conceitual. Como uma notável detentora dos processos poéticos da poiésis, o papel de Safo era apresentar o páthos, a paixão, o sentimento, que emergia das situações íntimas presentes em seus poemas.

Os sentidos mais abrangentes do termo páthos em seu campo semântico são sentimento forte, o que se experimenta ou suporta, experiência. A palavra é cognata ao verbo páscho, experimentar, vivenciar, sofrer. Há, portanto, uma ambiguidade no termo páthos que transita entre valores positivos e negativos. A paixão amorosa é boa, mas é tão forte que pode causar sofrimento, e, por extensão, vem daí o sentido de doença, também presente no campo semântico de páthos. Em nossa língua portuguesa, o radical da palavra aparece em composições que refletem essa ambiguidade, como nos 1) adjetivos a) simpático, do hipotético termo grego sympathikós, ${ }^{14}$ que qualifica o

\footnotetext{
${ }^{13}$ A palavra poiessis é formada do radical do verbo poiéo, criar, fazer, ligado ao sufixo -sis, que indica a própria ação expressa pelo verbo, dizendo respeito, portanto, ao próprio ato de criação poética. Nesse sentido etimológico, o termo se opõe ao seu cognato poíema, poema, que, com o sufixo -ma que indica resultado ou produto da ação, dize respeito ao processo acabado e, portanto, à obra. Filosoficamente, então, a poesia, como pura criação e processo subjetivo que se dá na mente, independe do poema, que seria apenas o canal concreto por onde o pensamento do autor se apresentaria.

${ }^{14}$ Não foram encontrados os exatos equivalentes desse e dos outros adjetivos nos dicionários de grego utilizados, o que permite inferir que os antigos não faziam uso de tais palavras, que, são, contudo, perfeitamente lógicas do ponto de vista formal. Da mesma maneira, não foi encontrado o substantivo pathología, mas foi encontrado o adjetivo pathologikós, que tem relação com as paixões, afecções ou doenças. $\mathrm{O}$ adjetivo, substantivado no feminino em he pathologiké (subtendido téchne, arte) diz respeito exatamente a ciência médica que trata das doenças. Cf. Bailly.
} 
indivíduo que tem a presença de páthos, ou seja, de sentimento, havendo, na formação do vocábulo grego, o prefixo grego sýn, que indica companhia ou simultaneidade, e o sufixo formador de adjetivos -ikos, que indica relação (o simpático, assim, é aquele que tem relação com o sentimento, ou seja, que o expressa ou experimenta); b) antipático, do hipotético adjetivo grego antipathikós, que qualifica o sujeito que se opõe ao páthos, por haver a presença do prefixo antí, que indica oposição; e c) apático, do hipotético qualificativo grego apathikós, que qualifica a pessoa desprovida de páthos, por meio da presença do $a$ privativo como prefixo, exatamente o alfa privativo do grego; e 2) no substantivo patologia, do hipotético vocábulo grego pathología, que, com a presença do radical lóg- de lógos, discurso, estudo, em sua composição, é um termo médico que diz respeito ao estudo das doenças. Safo parece sintetizar todos esses valores, pois o seu páthos se apresenta forte, na maior parte das vezes no sentido de uma paixão avassaladora que incendeia os amantes, podendo lhes causar um sofrimento que se apresenta como verdadeiros sintomas de uma doença, misteriosa, angustiante e, ao mesmo tempo, fascinante.

Qual objeto pode causar uma experiência geradora de um sentimento tão forte? Sissa e Detienne (p. 54) respondem esta questão, no momento em que detalham a forma como, no mundo grego, se dá a recepção de um objeto por alguém tomado de sentimento amoroso:

O ponto mais alto do amor, o momento mais intenso é, para um grego, o do impacto do olhar sobre um objeto jamais visto. É aí, nesse instante, que a dúvida, ou o temor de que a beleza seja excessiva e divina, exprime num mortal - Ulisses, por exemplo, ou ainda Anquises - o enlevoe o êxtase absoluto.

Essa passagem parece ter sido composta sob medida para se falar do poema a ser analisado neste artigo. As expressões desse páthos amoroso, proveniente de um indivíduo que está diante desse objeto jamais visto e que, por isso mesmo, lhe parece divino, podem funcionar, graças ao excesso que lhe são inerentes, como elementos transformadores da própria fisiologia humana. O homem, assim, será sofredor do extasiante impacto do olhar gerado pela presença do objeto amado. Esses sentimentos são absolutos no poema editado e catalogado por Page como fragmento 31 . 
O fragmento 31 (Page) sobreviveu ao tempo por ter sido citado por Longino em seu tratado de teoria literária denominado Do Sublime (cap.10, 2), que data do século II d.C.. No último verso do poema, introduzido pela conjunção adversativa allá, mas, há palavras que tornam difícil compreender o sentido do todo, devido ao estado corrompido do texto. Ao que parece, há uma fusão entre o conteúdo do poema e um comentário de Longino. De qualquer modo, levando-se em conta que os poemas do gênero lírico arcaico não eram muito grandes e que o próprio Longino está preparando sua conclusão a respeito da obra, pode-se dizer que o poema estaria quase completo, faltando apenas a última estrofe, o que é bem condizente com a presença da morte ao final da penúltima estrofe, que, ao que parece, fecha a sequência de sensações, concedendo ao texto um valor de ápice sentimental pela transcendência relacionada a um figurado fim próximo. Por esse ponto de vista, a última estrofe seria apenas uma espécie de conclusão. Segue uma tradução do poema feita pelo próprio autor deste artigo, com base na edição do texto grego e nos comentários empreendidos por Page, que possui poucas variações em relação ao texto do mesmo poema presente na edição da obra Do Sublime empreendida por Fyfe, também utilizada neste estudo para fins de cotejamento:

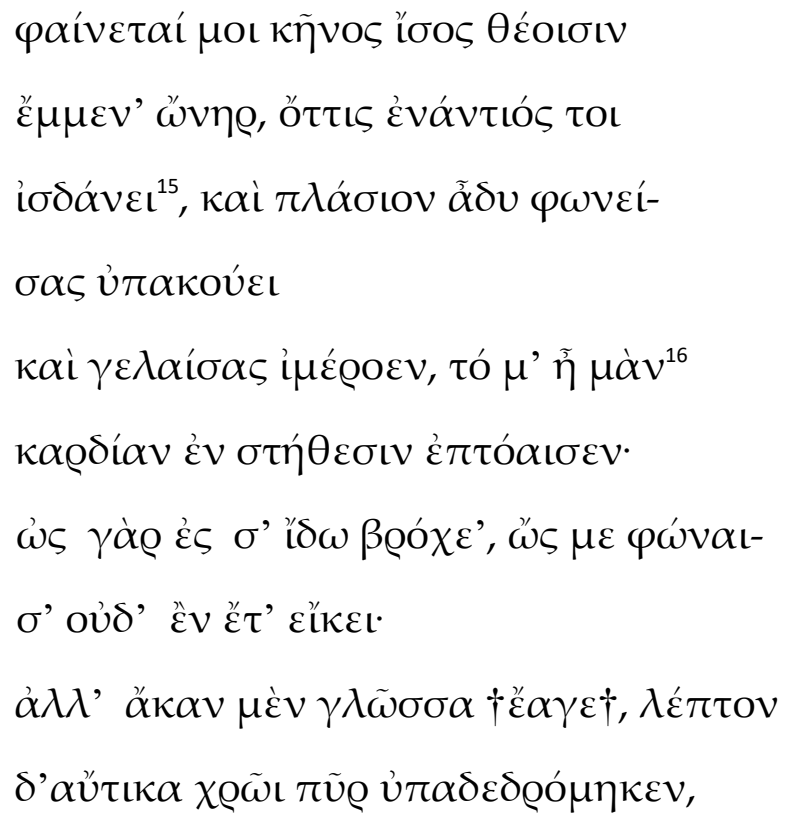

\footnotetext{
${ }^{15}$ A edição de Fyfe apresenta a variante izánei, com a consoante dupla dzeta, que nada mais é do que a união do delta com um sigma.

${ }^{16}$ A expressão $\underline{e}$ mén, sim verdadeiramente, é utilizada especialmente em juramentos, daí, a tradução por juro, quase como uma espécie de exclamação.
} 
TO E $\Lambda \Lambda$ HNIKO B $\Lambda$ EMMA - O OLHAR GREGO - No.1/2016 - UERJ - Brasil

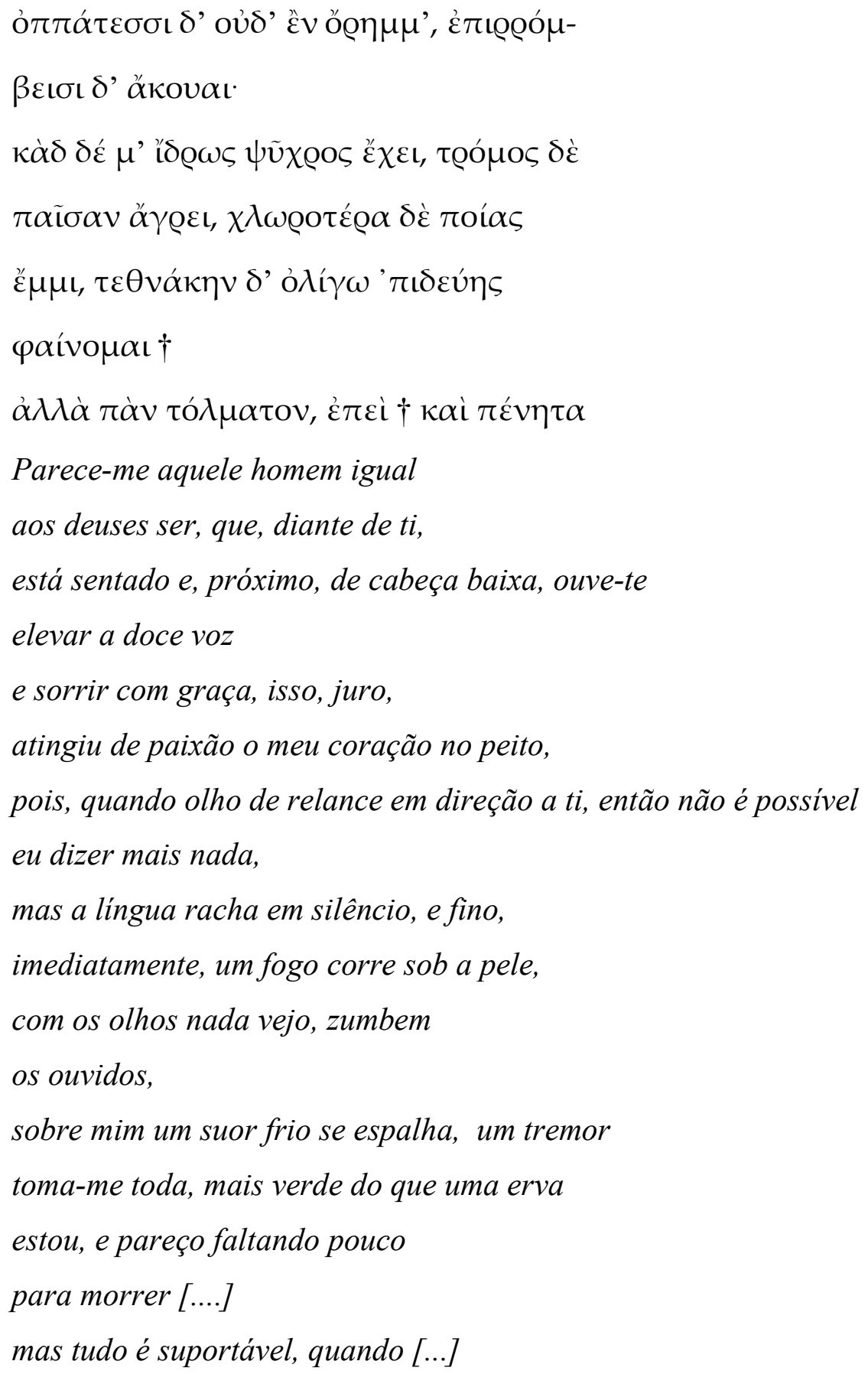

O dialeto é o eólico, com toda a sua complexa variedade de formas, e o poema se encontra em uma forma eólica conhecida como estrofe sáfica, pertencente à lírica monódica, que tem uma estrofe composta por quatro linhas, em que a quarta nada mais é do que um prolongamento do terceiro verso. A estrutura possui dois versos com onze sílabas em cada um (verso hendecassílabo), divididos em três pés, e um terceiro que, começando da mesma forma que os dois primeiros, possui onze sílabas seguidas de um prolongamento, composto por cinco sílabas (em um total de dezesseis). A estrofe sáfica 
é formada em seu dois primeiros versos por um pé trocaico, formado por dois troqueus simples $(-\mathrm{u}-\mathrm{u})$ associados a um dímetro coriâmbico catalético $(-\mathrm{u} u-/ \mathrm{u}--)^{17}$, ou seja, desprovido da última sílaba. A toda essa segunda extensão da estrofe sáfica, a saber, $-\mathrm{u} \mathrm{u}-\mathrm{u}--$, dá-se o nome de aristofânica, uma forma recorrente na poesia eólica. O terceiro verso, em suas onze primeiras sílabas, possui estrutura semelhante, havendo o prolongamento de cinco sílabas, sem cesura (pausa), formado por duas sílabas longas, duas breves e, por fim, mais duas longas, na forma conhecida como adônica $(-\mathrm{u} u--)$. Os dois primeiros versos da estrofe sáfica admitem, na última sílaba, a possibilidade de variação, podendo terminar em sílaba longa ou breve. Segue a estrutura da forma inteira:

$$
\begin{array}{lll}
-\mathrm{u}-- & -\mathrm{u}-\mathrm{u}-\mathrm{x} \\
-\mathrm{u}-- & -\mathrm{u} u-\mathrm{u}-\mathrm{x} \\
-\mathrm{u}-\mathrm{x}-\mathrm{u} u-\mathrm{u}-- & \\
-\mathrm{u} u-- &
\end{array}
$$

A alternância de sílabas longas e breves, em cada hendecassílabo e no último verso de dezesseis sílabas, determina, por fim, a melodia da estrutura, onde se pode observar ainda o comportamento da quarta sílaba do terceiro verso (primeiro pé), que pode ser breve ou longa. Para exemplificar agora na prática, é possível escandir a primeira estrofe do poema da seguinte maneira:

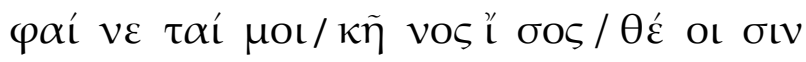

$$
\begin{aligned}
& -\mathrm{u}-\quad-/ \quad-\mathrm{u} u-/ \mathrm{u}-\mathrm{u}
\end{aligned}
$$

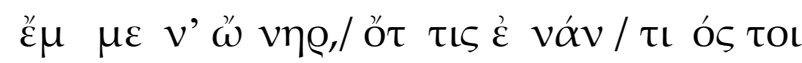

$$
\begin{aligned}
& -\mathrm{u}-\quad-/-\mathrm{u} u-/ \mathrm{u}-
\end{aligned}
$$

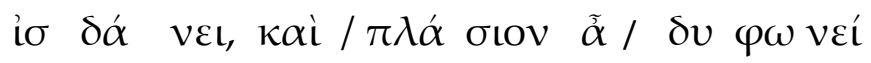

$$
\begin{aligned}
& -\mathrm{u}-\mathrm{u}_{-} / \mathrm{u} \mathrm{u}-/ \mathrm{u}-
\end{aligned}
$$

$\sigma \alpha \varsigma \dot{v} \pi \alpha$ koú $\varepsilon$

$-\mathrm{uu}--$

\footnotetext{
${ }^{17} \mathrm{Um}$ coriambo apenas é formado pelo pé - u u - , que é o núcleo da estrofe sáfica.
} 
No tocante ao contexto literário do poema, três personagens se fazem presentes: 1) um homem, de beleza semelhante a um deus; 2) a jovem ao seu lado, que fala e ri com delicadeza, que é a quem o eu poético se dirige; 3) o eu poético, a poetiza, que narra o que está acontecendo e emite sensações diante da situação. Por muito tempo, pensou-se que tal obra fosse um epithalámion ${ }^{18}$, ode nupcial, que era cantada para celebrar uma cerimônia de casamento. Segundo Page (1983, p. 30-1), essa constatação foi popularizada graças ao célebre helenista alemão Wilamowitz-Moellendorff, que via no poema uma cena de ciúme da parte do eu poético (Safo) para com sua jovem aluna, que estava prestes a deixar o convívio de sua escola para se entregar ao matrimônio. Por mais revelador e cativante que isso possa ser, o próprio Page (p. 31) refuta a tese, ao lembrar que a expressão kê̂nos óner , aquele homem, sempre possui no dialeto eólico o sentido de marido e ao mencionar que não há no vocabulário desse poema os termos comumente usados pela poetiza para se referir a cerimônias de casamento. Assim, a narrativa do poema, quase inexistente, levando-se em conta uma comparação com as extensas narrativas homéricas, se resume no fato de uma jovem estar ao lado do homem amado, possivelmente o seu marido, manifestando-se carinhosamente, diante dos olhos do eu poético, que se expressa de maneira apaixonada, extraindo de si todas as expressões do páthos amoroso, por meio de seu ato de compartilhar o enlace entre o casal apaixonado.

A direção a que a poetiza lança o seu olhar, a partir da linha 7, é objeto de discussão entre os especialistas. Alguns percebem uma situação de homossexualidade feminina, com presença de uma cena de ciúme da parte do eu poético. O olhar da poetiza, portanto, se direcionaria para a jovem que troca carícias com um homem, e todas as expressões de páthos que exprime, após a linha 7, seriam, assim, direcionadas a ela. Desde já, afirma-se que o autor deste trabalho não compartilha dessa opinião, o que é perfeitamente condizente com a proposta de análise apresentada neste estudo, pois o objeto jamais visto, citado por Sissa e Detienne, não pode ser a jovem conhecida de Safo, mas pode ser a situação que o encontro entre os dois seres, homem e mulher, em

\footnotetext{
${ }^{18} \mathrm{O}$ termo é formado do radical do substantivo thálamos, matrimônio, casamento, associado ao prefixo epí, sobre, antes, diante. Cf. verbete em GALVÃO (1994). Trata-se, assim, de um canto para ser feito antes ou diante de um casamento. Completa a palavra o sufixo -ion, que, sendo formador de diminutivos, indica, muitas vezes, um produto pertencente a um âmbito maior ou um elemento que serve a esse âmbito, como aqui, em o canto, a ode, do casamento.
} 
um determinado momento de relance, produz para o observador, o que determina uma cena completamente nova e jamais vista, mesmo que ambos fossem do círculo da poetiza. Deve-se frisar aqui que a utilização por Safo do acusativo adverbial bróchea, de relance, evidencia esse tipo de olhar que é, conforme o texto, em direção à jovem, o que pode ser interpretado como em direção a todo o contexto, e isso fica perceptível no uso da preposição es com o acusativo se (pronome pessoal de segunda pessoa do singular). Desse modo, o olhar não se mostra necessariamente direcionado apenas para a jovem. Assim, por meio dessa análise textual, defende-se que a poetiza estaria, na verdade, lançando o seu olhar para a situação como um todo, apreciando-a.

Fica, então, assentado neste estudo que esse clima amoroso estabelecido entre os amantes é exatamente o objeto jamais visto, nas palavras de Sissa e Detienne, formando-se, assim, como um impacto forte a ser sentido por meio do olhar da poetiza; mas, há ainda mais dois argumentos que talvez possam reforçar esse posicionamento. $\mathrm{O}$ primeiro argumento se apresenta no fato de que, desde o início do poema, o eu poético se coloca vislumbrando o todo, lançando o seu olhar, primeiramente, sobre o homem, lançando-o a uma beleza divina, com a expressão comparativa ísos théoisin, igual aos deuses, para, depois, acrescentar a mulher à imagem, com a expressão enántiós toi, diante de ti. No primeiro verso, ela não se expressa à jovem utilizando o pronome pessoal de segunda pessoa soi, não dizendo semelhante aos deuses este homem te parece. Fazendo uso do pronome na primeira pessoa moi, ela diz me parece, o que mostra uma compreensão da parte de poetiza do encontro dos dois amantes, que é o que parece ser admirado por ela no decorrer da ode. O segundo argumento é moldado, tendo-se em vista a própria linha 7 , o verso-chave para se debater a questão, e sua continuidade na linha 8. Há uma construção temporal formada da partícula hós com um subjuntivo, mas algumas traduções deixam escapar o valor comparativo inerente a esta partícula, principalmente, quando ela aparece duas vezes, como é no caso desse poema. Duas partículas hós em correlação podem ser traduzidas por como... assim também..., que o modo como Homero constrói, normalmente, seus símiles. Uma coisa é dizer quando te vi, fiquei apaixonada e outra coisa é dizer como te vi, assim também fiquei apaixonada. No primeiro caso, parece que quem fala está se declarando apaixonado por alguém. Já, no segundo caso, parece que quem fala está se mostrando apaixonado como a pessoa a quem se dirige. Esse tipo de comparação está presente no poema, de modo que seria possível aventar a hipótese de que a poetiza encontra-se apaixonada por ver a 
situação de enlace entre os amantes, compartilhando do sentimento da jovem. De qualquer maneira, a questão persiste, não podendo ser descartada a possibilidade de existir uma cena de ciúmes com conotações homossexuais, já que muitos estudiosos perceberam dessa maneira. Contudo, deixando de lado o objeto da paixão, seja ele o todo ou a jovem, é hora de se direcionar para as expressões apaixonadas propriamente ditas.

Em um tom crescente de gravidade, jorros de sentimentos vindos de uma notável inspiração poética inundam um poema, inflando-o até transbordar em expressões que transmitem ao ser humano calor, frio, tremor, audições confusas, falta de visão e uma sensação de proximidade com a morte que, longe de um teor mórbido, apresenta a vida em sua mais intensa pulsação. Tais manifestações fazem do poema em análise uma das mais originais e inspiradas criações da literatura grega, não faltando, entre os estudiosos, tentativas de se explicar como foi possível tal expressão literária.

Existe a proposta de uma linha de estudo nosológica que visa a dar conta das características apaixonadas presentes nos poemas de Safo. É seguindo tal proposta que Page opera em suas análises. Por esta linha, as sensações apresentadas seriam semelhantes a sintomas que assolam um indivíduo doente. Vale relembrar aqui que o termo páthos, sentimento forte, paixão, também significa doença. $\mathrm{O}$ uso de paráfrases talvez possa ajudar a compreender a presença de elementos que dizem respeito a verdadeiros sintomas em linguagem figurada que assolam o corpo durante a doença de algum indivíduo:

- o coração é atingido de paixão - coração disparado.

- não é possível dizer mais nada - desaparecimento da voz.

- a língua racha - língua com rachaduras em listras.

- um fogo corre sob a pele - calor, quentura no corpo, febre.

- nada se vê com os olhos - falta de visão.

- os ouvidos zumbem - audição falhando, sons estranhos no ouvido.

- um suor frio se espalha - suor frio saindo em excesso da pele.

- um tremor toma todo o corpo - tremores pelo corpo.

- parece mais verde do que uma erva - coloração estranha da pele.

- falta pouco morrer - sensação de falência de tudo e desmaio. 
A relação entre as sensações apaixonadas e o mundo médico, com seus complexos diagnósticos parece evidente. Contudo, este não é o único caminho possível de análise. Joaquim Brasil Fontes (2003, pp. 186-201), ao analisar o poema em pauta, se inclina para a influência homérica, também apresentada como importante por Page (1983, p. 28-30), dando à sua leitura o título de $O$ guerreiro covarde. Por meio de um estudo comparativo, Fontes mostra que as expressões apaixonadas do poema de Safo podem ser vista como transposições, para a poesia lírica, das expressões de medo que assolam os guerreiros de Homero em suas epopeias, o que faria com que um valor outrora negativo, ligado ao guerreiro, adquirisse um valor positivo, no contexto do gênero lírico arcaico.

O fato é que a originalidade de Safo impressiona, de modo que, quando a arte é verdadeira, as análises se ampliam, sem ser possível dar conta, por completo, do texto. Deve-se ressaltar que a análise nosológica e a análise comparativa, tomando-se por base a influência Homérica, não são excludentes. Poder-se-ia dizer que no poema existem ambas as influências, tanto a presença de conceitos médicos, modificados e estilizados por meio de um vocabulário poético, que teria todo um desenvolvimento posterior com Hipócrates, quanto a influência homérica, modelo de perfeição para toda poesia helênica. Nesse todo híbrido, talvez esteja parte do segredo da originalidade da poetiza Safo, que, desde a Antiguidade, era considerada uma artista do nível de Homero.

\section{BIBLIOGRAFIA}

ARISTOPHANES. Frogs. Greek text edited by F. H. Wall and W. M. Geldart. Perseus Digital Library. Disponível em http://www.perseus.tufts.edu/hopper/collections.

BAILLY, A. Dictionnaire Grec Français. Paris : Hachette, 1963.

BONNARD, André. Safo de Lesbos, décima musa. In Civilização Grega: da Ilíada ao Pártenon. Lisboa: Editorial Estúdios Cor, 1979.

DAIN, A. Traité de métrique grecque. Paris : Édition Klncksieck, 1965.

FONTES, Joaquim Brasil. Eros, tecelão de mitos: a poesia de Safo de Lesbos. São Paulo: Editora Iluminuras, 2003. 
GALVÃO, Ramiz. Vocabulário etimológico, ortográfico e prosódico das palavras portuguesas derivadas da língua grega. Rio de Janeiro; Belo Horizonte: Livraria Garnier, 1994.

HALLETT, Judith P. Sappho and her social context: sense and sensuality. In Reading Sappho: contemporary approaches edited by Ellen Greene. California: University of California Press, 1996.

LONGINUS. On the Sublime. Greek text edited and translated by W. Hamilton Fyfe. In the Poetics by Aristotle, On the Sublime by Longinus \& On Style by Demetrius. Harvard: Loeb Classical Library, 1999.

MALHADAS, Daisi, DEZOTTI, Maria Celeste \& NEVES, Maria Helena de Moura (equipe de coordenação). Dicionário grego-português. São Paulo: Ateliê Editorial, 2006, 2007, 2008, 2009, 2010. 5 v.

PAGE, Denys. Sappho and Alcaeus: na introduction to the study of Ancient Lesbian Poetry. Oxford: Oxford University Press, 1983.

RAVEN, D. S. Greek metre: an introduction. London: Faber and Faber, 1962.

SAFO DE LESBOS. Poemas e fragmentos. Texto grego com tradução de Joaquim Brasil Fontes. São Paulo: Editora Iluminuras, 2003.

SISSA, Giulia \& DETIENNE, Marcel. Os deuses gregos. São Paulo: Companhia das Letras, 1990.

SOARES, Marina Peixoto. As Rãs de Aristófanes: introdução, tradução e notas. 27/02/2014. 226 f. Dissertação (Mestrado em Linguística). Instituto de Estudos da Linguagem, Universidade Estadual de Campinas. Campinas, SP. 